Article published in: Business History 61(3), Issue 3: Health Industries in the 20th century, pp. 518-537.

\title{
China: The development of the health system during the Maoist period
}

(1949-76)

\author{
Roser Alvarez-Klee \\ Department of Economic History, Institutions, Policy and World Economy, University \\ of Barcelona, Barcelona, Spain
}

r.alvarez@ub.edu

\begin{abstract}
The Maoist period (1949-76) is considered an outstanding stage in Chinese history for its improvements in public health and welfare. In particular, the decrease in infectious diseases led to reduced mortality rate and increased life expectancy. This success can be attributed to the policies implemented in the health-care system during this period. However, different stages defined this process. The aim of this article is to determine whether health inequality in China was evident and consistent during the whole period. To determine this, provincial data were drawn on to undertake a comparative study in the allocation of health resources in different regions. In order to understand the dynamics of the health system during this period, the article focuses on one province in particular, that of Henan. The findings indicate that there was variation in the distribution of health resources among provinces during the Maoist era. The available figures indicate that there was a general increase in health resources in China. However, this did not prevent Henan province from experiencing a great decline in its health system during the Cultural Revolution (1966-76). Future research must be carried out to determine whether the inequality of health inputs in China during the Maoist period was positively correlated with the inequality of the health outputs nationwide.
\end{abstract}

Key Words: China; health institutions; Maoist period; Henan Province; Cultural Revolution

\section{Introduction}

Since the 1980s, the health of the Chinese population has improved and entered to a new nutritional and health transition linked to the spread of obesity, diabetes, and cardiovascular diseases ${ }^{1}$ (Deaton, 2015; Li et al., 2011; FAO, 2010; Popkin, 1997 and 2008; Popkin and Du, 2003). Some scholars suggest that the decline of infectious diseases 
among the Chinese population in recent decades might be associated with the increase in incomes, rather than the efficiency of the health system ${ }^{2}$ (Whyte and Sun, 2010; Kwon and Schafer, 2016; Li and Wei, 2010).

The transition towards a market economy after the late 1970s opened the way to the emergence of economic and social inequalities in $\mathrm{China}^{3}$ (Zhu, 2013; Keidel, A. 2009). In the health sector these inequalities are also evident between urban and rural areas ${ }^{4}$ (Evadrou et al. 2014; Biao, X. 2006; Feng et al. 2012; Yin and Lu, 2007; Zhao, 2006; Chou and Wang, 2009), as well as between different provinces ${ }^{5}$ (Li and Wei, 2010; Pan and Shallcross, 2016; Zhang, X. et al. 2015; Qin, X. and Hsien, C. 2014). This reflects the fact that health-care reforms have sometimes been deferred in order to concentrate on economic reforms ${ }^{6}$ (Zhu, 2013).

While health inequalities have been studied intensively for the years following the economic reforms, there is less literature on inequalities in the health-care system during the Maoist period (1949-76). Already in the 1980s, international health agencies claimed that China had taken the path of an epidemiological transition during this period, by reducing mortality and birth rates by 50 percent and 40 percent respectively, and increasing life expectancy from 44 years to 68 years $^{7}$ (White, 1998; Brown, Garcia, Liu, and Moore, 2012). This success was attributed to the great improvements in the health system in a country with lower incomes than in any industrialized country in the past, achievements that were described as unique in the developing world ${ }^{8}$ (White, 1998; Hipgrave, 2011).

During the Maoist period the clear objective was to spread an egalitarian health-care system to the whole country and reduce existing health inequalities, which had increased during the Republican era (1912-49) ${ }^{9}$ (Huang, 2013). However, the evidence indicates 
that, while there were health improvements at the national level, there were also great inequalities in health between the rural and urban populations ${ }^{10}$ (Huang, 2013).

A range of publications has concentrated on health outputs during this period ${ }^{11}$ (Slaff, 1973; Mason, Lavely, Ono, and Chan, 1996; Campbell, 2001; Banister and Zhang, 2005; Chen 2007; Hipgrave, 2011; Song, 2011), yet to my knowledge, few have studied the specifics of the distribution of health resources in China. ${ }^{12}$ (Jamison et al., 1984; Babiarz, Eggleston, Miller, and Zhang, 2015). Previous studies claim theoretically, that the geographical distribution of health resources contribute to health improvements in a society. ${ }^{13}$ (Andersen et al. 2011; Horev et al. 2004; World Health Organization, 2000). Therefore, the supply side of inputs (health resources) has an impact on the demand side of outcomes (access to health care). ${ }^{14}$ (Pan and Shallcross, 2016). The aim of this article is to investigate the distribution of health resources in China during the Maoist period.

Yip (2009) claims that the focus on economic reforms contributed to the deterioration of the quality of the health system and dismantled the near-universal health system of the previous decades. ${ }^{15}$ The aim of this article is to investigate whether the inequalities that exist in the health sector today were already present prior to the economic reforms. To this end, I will analyze the distribution of health-care resources among the different provinces in China, ${ }^{16}$ using the allocation of health resources to understand and evaluate the impact of the Maoist period health reforms.

A second aim of this article is to investigate the particular case of Henan Province, an agricultural region located in the Central Plain and characterized as one of the most populated provinces in the country (see Figure 1). The great demographic density of this region, nearly 95 per cent of whose population was rural throughout the Maoist period, adds particular interest to Henan as a case study. Therefore, the second question I aim to 
answer in this article is whether the distribution of health resources in Henan Province was constant at the different stages of the Maoist period.

\section{[Map 1 About here]}

During the 27 years of the Maoist period, the health system assumed different forms in response to demand and social structure, but more importantly, to the prevailing political circumstances as well. Four different phases can be identified: (1) the Initial Stage (1949-57); (2) the Great Leap Forward (1958-61); (3) the Adjustment Stage (196265); and (4) the Cultural Revolution (1966-76). At that time, health policies were focused on preventive medicine linked to national political campaigns and investments in medical institutions and medical personnel. In this article I examine the distribution of health resources at each of these stages. While a general increase in the supply of health inputs can be identified, the distribution of these resources reveals inequality gaps between the different provinces.

In this article, the overview of the health system in China during the Maoist period is based on institutional health indicators compiled from four Chinese statistical sources: Comprehensive Statistical Data and Materials on 50 years of New China (1950-1998) (Xin Zhongguo Wushi Nian Tongji Ziliao Xupian; 新中国五十年统计资料); and a new dataset including different health indicators from the Provincial Archive of Public Health Records (Weishengzi; 卫生志), the China Statistical Data Compilation (1949-2003), and the 1988 National Survey of Fertility and Contraception. ${ }^{17}$ For Henan, I have used the Henan Province Statistical Yearbook (1985) (Henan Tongji Nianjian; 河南统计年鉴) 
and Henan Provincial Gazetteers - 1985 Yearbook (Henan Xian Difang Zhi - 1985 Nianjian; 河南省地方志 -1985 年鉴).

The use of aggregate data published by the government implies certain limitations for this study. First, the reliability of official statistical data in China cannot be assured, especially for the Maoist period. I address to this issue in Section 3, where in certain provinces some figures appear to have been exaggerated, particularly during the GLF stage. Secondly, the aggregated data cannot be used to assess the development and availability of health resources at the micro-level. Recent studies concerning the state of the health system following the economic reforms use household data such as the China Health and Nutrition Survey (CHNS), China Health and Retirement Longitudinal Study (CHARLS), China Institute for Income Distribution dataset (CHIP), and China Family Panel Studies (CFPS). The data in these datasets lack information on the allocation of health resources during the Maoist period, but previous studies have used the CHNS data on heights, as an indicator of health. They show a similar trend to the final conclusions of this study, that is, of improvements in health and health resources nationwide, but with great inequality between provinces and at different political stages during the period under study. ${ }^{18}$ Finally, the provincial gazetteers provide valuable information on developments in the supply of health resources, described in Section 4.

This article is divided into five sections. Section 2 describes the different policies and health institutions that were introduced in China during the Maoist period, based on the four different stages listed above. Section 3 analyzes the data at both the national and provincial levels. Section 4 focuses on the development of the health system in Henan Province specifically. Section 5 offers some final conclusions.

\section{Health system: policies, campaigns, and institutions}




\subsection{The Initial Stage (1949-57)}

When Mao Zedong came to power in 1949, China's health situation was in a precarious situation. The scarcity of health institutions and the unequal distribution of health resources between rural and urban areas left a great percentage of the Chinese population with no access to health-care. ${ }^{19}$ Immediately after the establishment of the People's Republic of China (PRC), the Chinese Communist Party (CCP) focused on the development of a state-run health-care system based on the communist ideals developed during the revolutionary era (1927-49), in defense of a public health system governed by policies concerned with the control of epidemics. In November of that year, the Ministry of Health $(\mathrm{MOH})$ was established as the organization responsible for health, with subnational local branches. Labour insurance and government health insurance were introduced in the early 1950s, with free health care being provided to industrial workers and families, government employees, teachers, and students. However, because of financial constraints, the central government allocated only 1.2 per cent of the national budget to the health-care sector, rapidly creating congested health services demand and limitations on state finance. Ironically, this situation widened the gap between the urban and rural areas, leaving the peasants behind.

The central government was aware of the precarious situation in the rural areas and its own financial constraints. As a result, it became important to concentrate on the prevention first policy, which insisted in averting the spread of infectious diseases, thus allowing the state "gain political capital by reducing human suffering". ${ }^{20}$ (Perkins and Yusuf, 1984, pp.135). The means to accomplish this objective relied on the state's control of society, especially in the countryside, by launching patriotic health and mass mobilization campaigns to increase health awareness. While at the beginning of the $1950 \mathrm{~s}$ private health facilities still existed, by the mid-1950s the healthcare system had become 
mostly an activity of the state. The MOH identified twenty communicable diseases, but due to the financial and institutional constrains, only cholera, smallpox, and the plague were targeted as a priorities. ${ }^{21}$ (Huang, 2013,pp.44). In addition, by 1957 the fight against schistosomiasis and venereal diseases had become a central goal. At the end of this stage, two thirds of all the counties in China had an epidemic prevention station (EPS) applying communicable disease control (CDC) programs, vaccination, and environmental sanitation and hygiene. ${ }^{22}$ (Hipgrave, 2011, pp.225). While the prevention first policy was successful in the long run (for example, the last outbreak of smallpox was in 1960, twenty years before its global eradication) ${ }^{23}$ (Xu, 1994), the health-care system had a long way to go in providing the rural population, with curative treatments and tackling infectious diseases not targeted by the CDC programs, which remained a latent problem. Nevertheless, by the end of the initial stage of implementing the health-care system, Mao had won popularity among peasants and local officials, to the extent that he felt powerful enough to weaken the intervention of the MOH bureaucracy, as he understood it, thus acquiring complete authority to supervise health activities in the years that followed.

${ }^{24}$ (Huang, 2013, pp. 45; Li Rui, 1999, pp. 276; Perkins and Yusuf, 1984, pp. 137).

\subsection{The Great Leap Forward (GLF) (1958-61)}

Policies during the GLF were basically concentrated on collectivizing China's socioeconomic structure. The establishment of a commune system in rural areas, controlled politically, clearly changed the social and economic structure of the system and also had an impact on health-care. Already in the mid-1950s some communes in Central China, including Henan, adopted the so-called Cooperative Medical Schemes (CMS), which provided free health-care for the whole of the rural population. By the end of 1958, all cooperatives had adopted the CMS. Mostly decentralized, free medical services, financed by county and commune budgets, provided peasants with an incentive 
to adopt the system of collectivization system in its entirety. The rural public health-care system was supported by two main sources of funding: the commune members' annual fees, and the revenues collected from the agricultural production. The former provided only very low revenues and ultimately became practically non-existent, while the later was only likely to be effective if the primary sector of the economy at the provincial level was successful; this proved not to be the case, and three years after the GLF's policies had been implemented, the system had reached a state of collapse.

The prevention first policy nonetheless remained the focal domain in the public health system during the GLF. One of the most emblematic hygiene campaigns was the so-called Four Pests, which made the wiping out of mosquitos, flies, rats, and sparrows a top state priority in order to eliminate schistosomiasis. Avoiding most of the technical and professional leaders of the $\mathrm{MOH}$, Mao proclaimed the mobilization of rural labour to catch and kill the four pests. ${ }^{25}$ By the end of 1959, fifty per cent of patients suffering from schistosomiasis disease had been cured. ${ }^{26}$ However, the Hundred Flowers Campaign in 1956 and the Anti-Rightist Campaign in 1957 "set in motion a bandwagon effect with localities competing for rapid elimination of schistosomiasis". ${ }^{27}$ The same pattern was evident in the setbacks to agricultural production during this period, one of the main reasons for the famine in the GLF. ${ }^{28}$ Low nutritional intake and the unprecedented consumption of non-edible goods during the subsistence crisis increased disease levels, especially in the rural areas. By 1961, the decrease in the amount of revenue allocated to health resources could not support the increased demand for medical provision, leading to greater fiscal constrains with clear negative effects for maintaining an efficient healthcare system. The national budget also fell during the period due to the increased investment in the secondary sector in urban areas, meaning that the communes and counties could not turn to the central government for financial assistance. To confront the 
problems of welfare funding, local cadres considered increasing peasant's fees for access to health, but levels of poverty at the commune level had reached their peak. In addition, contrary to Mao's initial objectives, the health gap between the urban and rural areas widened due to intensification of the industrial sector.

\subsection{The Adjustment Stage (1962-65)}

After the GLF Famine, the state and local governments worked to improve the agricultural system in order to increase food production based on more bureaucratically oriented policies. This was the beginning of the modernization of the primary sector, which would be pursued with greater force in the mid-1960s. Collectivization was relaxed; but the setbacks during the GLF met their response in Mao's silence on healthcare issues from July 1960 to August $1964 .{ }^{29}$ The subsistence crisis at the previous stage weakened the rural population's ability to engage in mass mobilization on preventive health issues, and patriotic hygiene campaigns were discouraged until 1964. During this new stage, commune health centers declined in all respects, and the gap between rural and urban areas increased. By 1964, 30 per cent of government health-care funding was being allocated to urban areas, and only 16 per cent to rural areas. In addition, 90 per cent of senior health workers were appointed at or above the county level, leaving behind residents in the communes, which constituted the greater part of the Chinese population. ${ }^{30}$

\subsection{The Cultural Revolution (1966-76)}

By the mid-1960s, Chairman Mao felt he was losing political control after leaders such as Liu Shaoqi and Deng Xiaoping had gained political influence with revisionist policies during the adjustment period to overcome the failures of the GLF. In 1964, the coup against Nikita Khrushchev in the USSR alerted Mao that a similar outcome could take place in China. At this point, loyalty towards party personnel became more important 
than its policies, and Mao concentrated all his power on preserving its leadership. ${ }^{31}$ This political environment produced a new stage in China that lasted for ten years: the Cultural Revolution (CR). During this decade, major changes took place in the country that involved political repression, which also affected the health-care system. By the mid1960s the confrontation between Mao's revolutionary views and the MOH's bureaucratic practices returned to the situation of the mid-1950s. At this point, Mao's major concern regarding health issues was the existing inequalities, between the rural and urban areas, and he referred to the MOH as the "Ministry of Urban Lords". 32

Mao's political agenda had two main policies for the health system. The first was to transfer a large number of professional doctors from urban to rural areas. The second was to restructure the education of medical technical personnel by reducing the number of years of training from six- and eight-year programs to three-year programs. ${ }^{33}$ These measures faced great opposition from the MOH. However, between 1968 and 1973, after the fall of Liu Shaoqi and Deng Xiaoping in 1967, the MHO lost all its influence in the policy-making process. Mao's most engaging health program at the time was the barefoot doctor (BFD) program, established as national policy in 1968 and regarded as an effective measure solving the problem of the scarcity of doctors in rural areas and minimizing costs. $^{34}$

The typical BFD was actually a peasant who provided basic health care, sanitation, health education, and preventive medicine at the brigade and working team levels. Many BFDs, who received credits for work points in health and agriculture, were urban medical personnel transferred to rural areas. In 1965, fewer than 19,000 medical personnel were sent to the countryside; at the end of the period, the figure peaked at 1.8 million. ${ }^{35}$ The package, mainly founded by brigades, provided a more continuous service and achieved a higher population reach than the preventive campaigns of the $1950 \mathrm{~s} .{ }^{36}$ Together with 
midwives and physicians, the new system adopted a bottom-up rather than top-down approach and responded to the failures of the GLF, using fees and other market mechanisms to prevent overuse and unnecessary use of health services. ${ }^{37}$ The BFD program remained in existence until the 1980s.

\section{Analysis of the data}

\subsection{National statistics}

During the Maoist period, great achievements in health were related to the improvement of health institutions dating from the previous Republican era and the construction of new ones. From the establishment of the PRC in 1949 to 1976 , the number of health institutions increased by 23.2 per cent (see Graph 1 ). These institutions included major investment in hospitals and clinics, and to a lesser extent also in sanitary and epidemic stations, sanatoriums, specialized prevention and treatment centers and stations, and maternity and child-care centers.

\section{[Graph 1 About here]}

Maternity and child-care centers represented a low proportion of total health bodies, but they experienced the greatest increase during the period, reaching at 36 per cent. The introduction of health institutions was one of the main factors in reducing infant mortality in China. Based on public health records, from 1950 to 1976, the infant mortality rate and the mortality rate of children under five years old decreased by 62 per cent and 90 per cent respectively. Figure 2 illustrates the great decrease in infant mortality in the different regions and at the different stages between 1950 and 1985. Most provinces reached infant mortality rates higher than 55 per thousand in the initial stage (1949-57). The excessive deaths of infants under a year old in China during the GLF are attributed 
to the critical effects of the Great Famine. During the Cultural Revolution, over 50 per cent of the provinces indicated on the map decreased their infant mortality to rates to between 15 per thousand and 35 per thousand. By the initial years of the reform stage, only Guizhou Province still had rates of infant mortality higher than 35 per thousand.

\section{[Map 2 About here]}

Nearly one million midwives were re-trained, reducing newborn and puerperal infection rates, including the rate of neonatal tetanus. ${ }^{38}$ The increase in women's enrolment in education was also positive for the reducing infant mortality, as it not only contributed to the provision of health information, but also increased the age at marriage for females from 17.5 years in 1952 to 22.3 years in $1980 .{ }^{39}$ Sanitation and anti-epidemic stations and specialized prevention and treatment centers also experienced representative increases, reaching 26.3 per cent and 25.7 per cent, respectively. As previously mentioned in Section 2, the prevention first policy played a major role in reducing infectious diseases.

Medicine and chemical test laboratories and medical science research institutes, not shown in Graph 1 due to their low representation in the total figures for health institutions, also increased by 38.6 and 34.8 per cent respectively. These figures are not representative in the whole picture for two main reasons. First, even though Western medicine started to play a greater role in the health system during the Maoist period, Chinese traditional practices still had greater representation. Statistical records show that until 1970 more doctors were practicing traditional Chinese medicine than Western medicine. ${ }^{40}$ This situation was reversed in 1971 , when there were 206,000 doctors of traditional Chinese medicines and 241,000 doctors of Western medicine. By 1976, the figures had reached 236,000 and 308,000 respectively. The second explanation is related 
to the intellectual and scientific setbacks experienced during the Cultural Revolution. The limits placed on the $\mathrm{MOH}$ in the process of policy-making had a great negative impact on the developments in this particular area. It was not until 1978, with the new economic reforms of Deng Xiaoping, that medical research would win a representative share of the health system.

Despite the remarkable increase in the number of health institutions during the Maoist period, the pace of growth at each stage of the health system differed greatly. The most outstanding increase came at the initial stage, with a 55 per cent growth rate; no other stage was to reach such a representative rate. In fact, after 1958, the growth in health institutions not only slowed to 8 per cent during the GLF, but also suffered stagnation and a decline in growth after 1962 (0.7 per cent growth during the adjustment stage and 2.4 per cent decline during the Cultural Revolution). Such percentages show the fiscal defaults since the beginning of the 1960s, previously explained. However, in Graph 1 we can see that that in any case the figures were lower than in the achievements of 1957. Even in 1971, with fewer health institutions being registered since 1959, the figures are higher than in 1957. It should also be noted that the decrease in the number of health institutions after the mid-1960s is to be explained by a decline in the number of clinics, despite which the number of hospitals almost doubled, from 35,500 in 1959 to 65,000 in 1970.

The number of beds in health institutions is another indicator of improvements to the health system. From 1949 to 1976, the number of beds available increased by 18.7 per cent. Graph 2 shows that, despite the increase in the number of beds in health facilities in the initial stage, the figures are not representative when taking the total population into account. In addition, in light of the clear inequalities between rural and urban areas, we should stress that figures did not exist for the countryside. Even during the Cultural 
Revolution, when a great effort was made to reduce the gap between rural and urban areas, two thirds of these resources were allocated to the latter. During the GLF there is a clear increase in the number of beds per ten thousand persons, which can be attributed to the change in the population structure, given that this particular period is characterized by high mortality rates (the levels of mortality and infant mortality in China increased to 15 per thousand and 66 per thousand respectively). The situation remained one of stagnation until the early 1970s, when there was a constant increase in the number of beds. By the end of the Maoist period, records give a figure of twenty beds per ten thousand persons.

\section{[Graph 2 About here]}

\subsection{Provincial differences in health endowments}

Health policies were implemented nationwide during the Maoist period. Yet, the decentralized system translated into provincial differences in fiscal revenues and, therefore, investment in local health-care systems. ${ }^{41}$ Records show that the adoption and construction of health institutions remained very low in Western China (especially Qinghai, Ningxia, Xinjiang) (see Table 1). Qinghai and Ningxia provinces did not reach 1 per cent share of the total health-care facilities in the country for the whole period. A similar pattern is shown for Xinjiang and the southern region of Hainan until the decade of the 1960s. Even then, the share remained lower than 2 per cent. Table 2 shows a similar picture when the share of total hospitals in China is examined. Several features may explain this pattern. First, the western regions were, as they still are today, low-income provinces with high levels of poverty. Secondly, although these provinces constitute a great proportion of China's total geographical area, most of its land is infertile and cannot be used for agriculture. Given that, at some stages in the Maoist period the communes 
based partially on agricultural production funded the health system in rural areas, it is understandable that the budget for health-care would be lower in these regions. Thirdly, the western provinces are not only less populated, but a greater proportion of minority populations are settled in these regions. Unbiased political mechanisms might be used in these cases.

In Section 2 I mentioned how during the GLF requiring the different localities to compete in the areas of health and agriculture allegedly led to actual socioeconomic achievements being exaggerated. Figures for the total number of health institutions and hospitals recorded during the GLF prove to be misleading when the share by province is computed. Such estimations suggest that provinces such as Henan, Anhui, Shandong, Hunan and Shaanxi may indeed have exaggerated their statistics regarding the number of hospitals each had (see Table 1). Many of the figures in these regions are exaggerated by as much as a facto of ten, going back to the same records as at the initial stage during the adjustment period.

\section{[Table 1 About here]}

A similar pattern is observed in Table 2, which focuses all health institutions. While the increases in these figures are not as evident as when the figures for hospitals alone are examined, there is a general and representative increase in the proportions of institutions in almost all regions. The absolute figures indicate that the total number of hospitals during the GLF increased to 247,000 units from 52,000 in the previous stage. It has proved difficult to determine the reasons why these figures increased at such great rates during the GLF and with such variations across provinces. In any case, the alleged over-reporting during the GLF shown in Tables 1 and 2 suggests that the number of health 
institutions had had a representative increase since the beginning of the 1960s and that the number of hospitals reached its peak during the Cultural Revolution. All through this twenty-seven years period, Hunan and Hebei Provinces seem to have had the greatest shares of the total of health institutions and of hospitals respectively. Yet both regions had high infant mortality rates during this period.

\section{[Table 2 About here]}

From 1949 to 1976, the number of medical technical personnel and doctors increased by 8.5 per cent and 5.4 per cent respectively. Even though the highest figures are recorded after the $1960 \mathrm{~s}$, the growth rate is higher in the initial stage (4.7 per cent) and the GLF (4.6 per cent), when compared to the remaining two stages (2.6 per cent). While the increase was representative, the allocation of doctors was not equally distributed nationwide.

Figure 3 illustrates the development of the allocation of doctors in China from 1949 to 1985 . It is notable that during the initial stage (Figure 3 (a)) there is a low share of doctors per ten thousand inhabitants in most regions, with the exception of Shaanxi, Hubei, Shanghai, and Beijing. During the GLF Shanxi and Shaanxi increased the rate to 27 and 20 doctors per ten thousand inhabitants respectively. While there was a general increase in the allocation of doctors nationwide, Liaoning and Guangdong reduced their share of doctors, while Tibet and Gansu Provinces remained with the same proportion (see Figure 3 (b)).

Figure 3 (c) and (d) show a clear decline in the allocation of doctors during the Cultural Revolution. While the share of doctors is greater during this period than at the initial stage and during the GLF, the adjustment stage seems to have had a greater 
allocation of this type of medical resources. However, while we notice an increase in the share of doctors at the recovery stage, previous publications indicate that the allocation was distributed mainly in urban areas, thus widening the gap between them and the rural areas.

\section{[Map 3 About here]}

During the Cultural Revolution 20 out of 28 provinces decreased the share of doctors by between 2 per cent in Zhejiang Province and 41 per cent in Henan Province. During the initial years of the reform stage, the allocation of doctors per ten thousand persons increased to as high as 18 per cent in Ningxia and 154 per cent in Tibet. Note that only Anhui ( 2 per cent increase), Fujian (1 per cent increase), and Gansu (no increase) remained stagnant in terms of health allocation. Indeed, Gansu Province had very low share of doctors ( 0,1 doctors per ten thousand inhabitants) and a high infant mortality rate (70 per thousand) throughout the Maoist period.

Annual figures show that the number of medical personnel and doctors per ten thousand persons declined during the initial stage of the Cultural Revolution, but recovered again at the beginning of the 1970s to the end of the Maoist period (see Graph 3). There are no specific notes in the official statistics showing whether the BFDs were included in the category of doctors or in some other category of medical personnel. In any case, while a great emphasis was placed on the BFD program covering rural areas, there was also a strong campaign to reduce the number of years of training, leading to the shutting down of a great number of medical universities nationwide. Indeed, the number of medical personnel per ten thousand persons, including doctors, in the early 1970s dropped to rates very close to those of 1957 . This decline, which started in 1966, was 
reversed after 1972, and by 1976 the number of medical personnel per ten thousand persons exceeded all figures registered in any previous year.

\section{[Graph 3 About here]}

\section{Henan province}

During the Republican era, most practitioners of traditional Chinese medicine (TCM) were working in the private sector, either in self-owned offices or in private hospitals that combined TCM with Western medicine. Based on Henan Province's gazetteers, nearly 2,700 private practitioners were located in the province, though only 154 had been approved and registered by the Provincial Health Department. With the establishment of the People's Republic of China, one of the main focuses of the new government was to promote the practice of TCM once again. Henan Province concentrated on the production of medical herbs and established a state-owned pharmaceutical industry open to the local and national market.

By 1954 the local government had already invested in the construction and spread of different hospitals and clinics within the province that concentrated on the practice of TCM, many of which were combined with Western medicine. While this practice developed during the 1950s and early 1960s, during the Cultural Revolution the work was paralyzed. Indeed, one third of the TCM hospitals closed down, many clinics had their licenses revoked, and about 150,000 practitioners in the sector were relocated. TCM policies were implemented again in 1978, in circumstances of their rapid development, which spread to different prefectures in the region and acquired greater importance in the 1980s. 
While several studies define the BFD program as a positive system established during the Cultural Revolution, statistical data shows that Henan Province lagged behind during this period in health levels. Graph 4 shows a representative decrease of the number of doctors per 10,000 inhabitants. The decline started at the beginning of the Cultural Revolution and did not recover to the levels of the mid-1960s until the early 1980s. During this period the share of doctors declined from 9.5 doctors per 10,000 inhabitants in 1965 to 5.8 per 10,000 inhabitants in 1976, reaching its lowest point in 1971 with 4.8 doctors for every 10,000 inhabitants. Indeed, during this time many hospitals in the province closed down, and all the progress made in preventive medicine in previous years was wiped out. The provincial gazetteers show that during the Cultural Revolution, thirteen hospitals were either merged or closed down. ${ }^{42}$ Also, the development of medical technology stagnated until the beginning of the 1970 s.

\section{[Graph 4 About here]}

The provincial health and epidemic stations were reduced from 153 units in 1965 to 62 units in 1969. Therefore, prevention of tuberculosis and other parasitic diseases ended until the beginning of the 1970s. Between 1956 and 1962 a "seven year plan to eliminate malaria" was implemented, but it failed in Henan due to the GLF. However, by 1964 the province had become one of the greatest successes nationwide in malaria eradication, reducing the cases to 1.3 per cent. Nonetheless, the interruption of malaria treatments during the Cultural Revolution increased the rate of malaria cases and gastrointestinal diseases increased by more than 40 per cent in some prefectures. At this point, Henan Province became one of the worst provinces in China. 
While during the initial stage of the Maoist period great stress was placed on maternal health care, during the Cultural Revolution maternal and child health-care institutions also suffered a substantial decline, with nearly 70 per cent of stations closing down between 1965 and 1969. Most women lost their labor protection, which had been introduced at the beginning of the Maoist period by the local Health Department and the Provincial Women's Federation: pre-natal and post-natal leave was abolished, and female health rooms and nursing rooms in factories and mines were closed down. These developments contributed to an increase in the incidence of common disease among women and a greater deterioration in child health-care. By 1975, child mortality and maternal morbidity had increased to figures higher than the national average. Between 1976 and 1978, Henan Pediatric Medical College conducted a survey of 100,000 children between 0 and 14 years old in eighteen brigade teams and three cities. The results increased the death rate among children between 0 and 12 months to 25.7 per cent. The death rates for cohorts aged 1 to 3 years old, 4 to 7 years old, and 8 to 14 years old were 2.9 per cent, 1.3 per cent, and 0.6 per cent respectively. The recovery begun in 1978, when provincial health bureaus developed new standards for women's and children's health-care, with a greater focus on the rural areas.

\section{Conclusions}

The Maoist period is characterized by improvements in health indicators nationally, leading to the demographic transition in China and increased life expectancy. However, between 1949 and 1976, institutional changes can be divided into four different stages in the health-care system. The GLF (1958-61) was by far one of the greatest setbacks in China from every perspective, including health and welfare. In terms of health institutions there were representative increases, but there are irregularities in the data, a problem noted in subsection 3.2. Also, while health institutions increased nationally 
during the Cultural Revolution (1966-76), the number of medical personnel per ten thousand persons declined form 1966 to 1972, reaching the same levels as in 1957. The decade of the Cultural Revolution is divided into two stages: a first period, from 1966 to 1971, when allocation of health resources suffered a decline; and a second period, from 1972 to 1976, when the distribution of health resources increased at an accelerated rate.

During the Maoist period, improvements in the health-care system were not positive in all provinces. Indeed, allocations of health infrastructure in the western regions, such as hospitals and clinics, were not representative nationwide. This is a problem, given that the population of the western regions is sparser than in other Chinese regions and therefore a greater number of hospitals and beds per person in such regions should reduce inequality nationally, a setback that still has to be solved in China ${ }^{43}$ Still, the allocation of doctors per ten thousand inhabitants was representative in comparison to other provinces located in the southeast of the country, especially after the adjustment stage (1962-65).

In order to acquire a better understanding of existing health inequalities and the development of the health system in China, the case of Henan Province has been analyzed in this article, based on provincial gazetteers and statistical yearbooks. This province was chosen due to its middle position in China regarding well-being and its high population density. Official sources show that the Cultural Revolution represented a great leap backwards in terms of health, as denoted by the representative increase in infectious diseases and infant mortality. This was mainly due to the restrictions on the development of the sector. Therefore, in the case of Henan Province, this particular decade was a backward stage not only for education, as previous studies have invariably indicated, but also for the structure and efficiency of the health system. Yet other regions such as Gansu Province had a lower share of health resources and higher rates of infant mortality. Such 
conclusions prompt a new question, namely whether the BFD system implemented in the mid-1960s was indeed a well-functioning system in all-Chinese provinces, as past studies have indicated.

There are some limitations to this article that must be mentioned. First, the data it uses give no information about exactly where the health resources were allocated within each province, making impossible to determine whether the health inputs were equally distributed between the urban and rural areas, nor which counties and/or districts were better provisioned. Therefore, it cannot be determined whether access to health resources was equal throughout the local population. Secondly, there are no specific figures about the number of barefoot doctors during the Cultural Revolution. While this might prevent the figures during this period being clearly interpreted, it must be remembered that not only did the number of doctors and medical personnel per ten thousand inhabitants decline at this stage, so did the quality of the health inputs because of the fewer years spent in medical education and research. Finally, so far, it has not been possible to make a clear correlation between the inequalities of health inputs and the health outputs; further study is needed in this regard. In any case, we have found a relationship between the increase in allocations of health resources and the decline in the rate of infant mortality nationwide.

Despite these limitations, it has proved possible to answer the questions set out in the introduction to this article. First, contrary to Mao's aim, to reduce health inequalities in China, variation was indeed found in the distribution of health resources among the provinces before the spread of the economic reforms at the end of the 1970s. Secondly, using Henan Province as a case study, it can be concluded that, while health inputs increased from 1950 to 1976, the health policies implemented during the GLF and, especially, the Cultural Revolution simply produced a deterioration of the health system in the region. Future research must be carried out to determine whether the inequality of 
health inputs in China during the Maoist period had a positive correlation with the inequality of the health outputs nationwide.

\section{Figures}

Map 1. Mean population in China by province during the Maoist period (1949-76) 


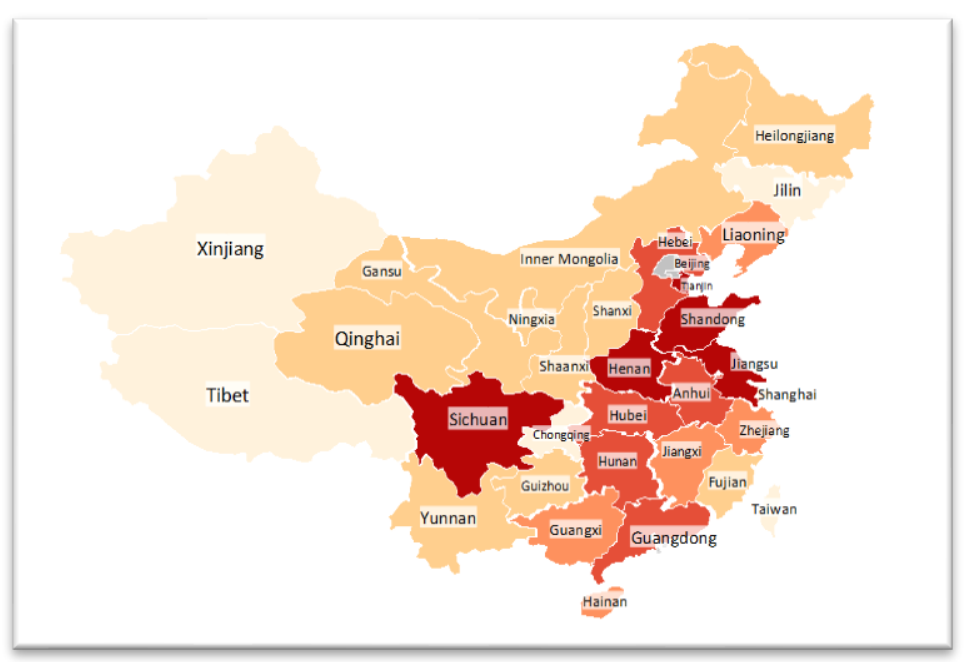

\begin{tabular}{|c|c|c|}
\hline & 0 & $10,000,000$ \\
\hline & $10,000,000$ & $20,000,000$ \\
\hline & $20,000,000$ & $30,000,000$ \\
\hline & $30,000,000$ & $40,000,000$ \\
\hline $40,000,000$ & $60,000,000$ \\
\hline
\end{tabular}

Source: Author's elaboration based on the Comprehensive Statistical Data and Materials on 50 Years of New China (19501998)

Graph 1. Health institutions in China (1949-85)

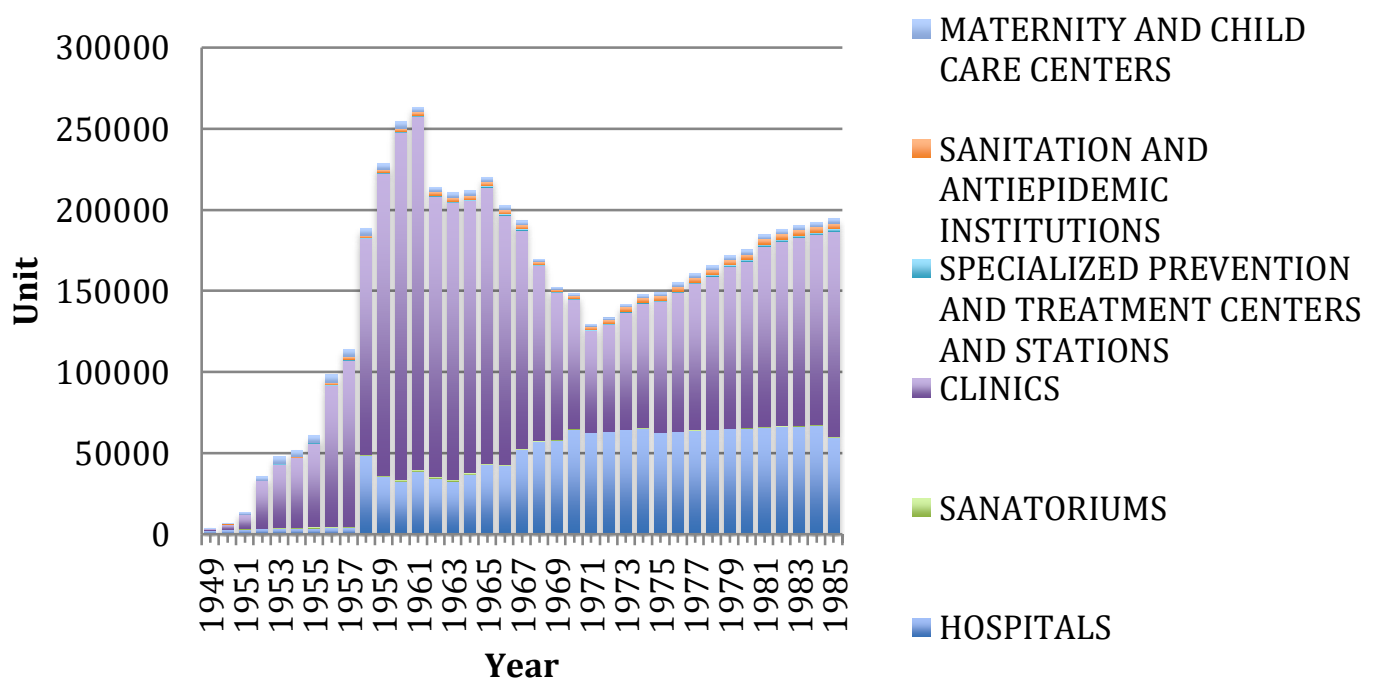

Source: Author's elaboration from the Comprehensive statistical data and materials on 50 years of new China (1950-1998) 
Map 2. China's Infant mortality rate per mil (1950-85)

(a) Initial Satge (1950-57)

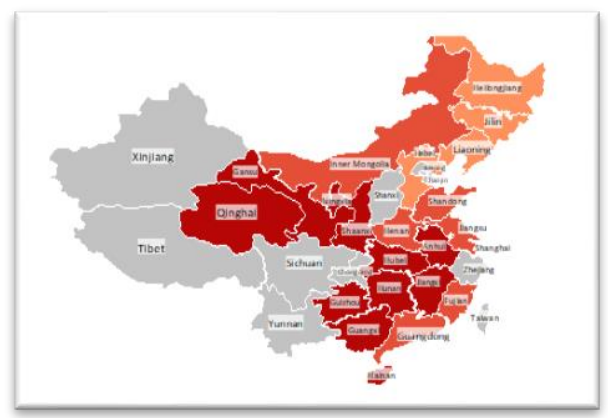

(d) Cultural Revolution (1966-76)

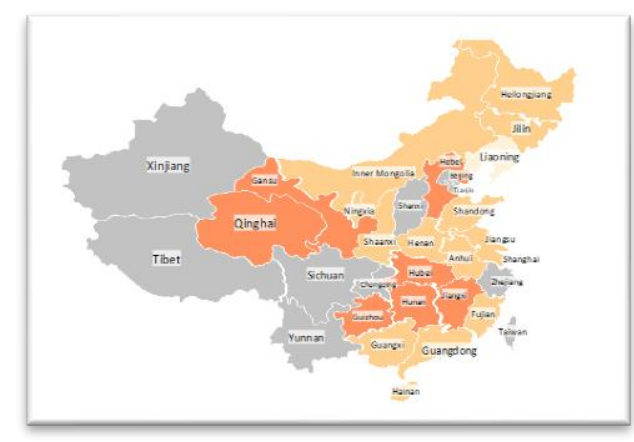

Source: Author's elaboration from the Provincial Archive of Public Health Records (c) Adjustment Stage (1962-665)
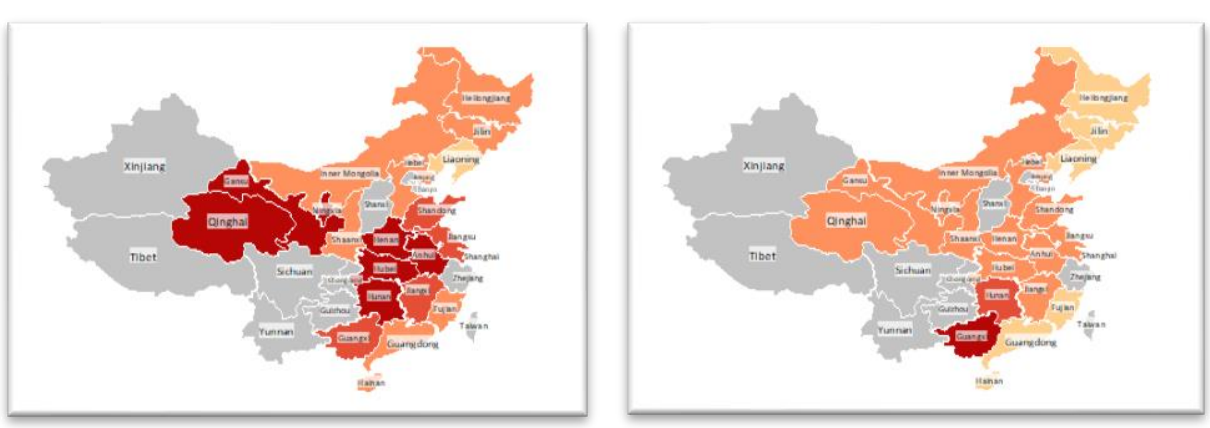

(e) First Economic Reforms (1977-85)

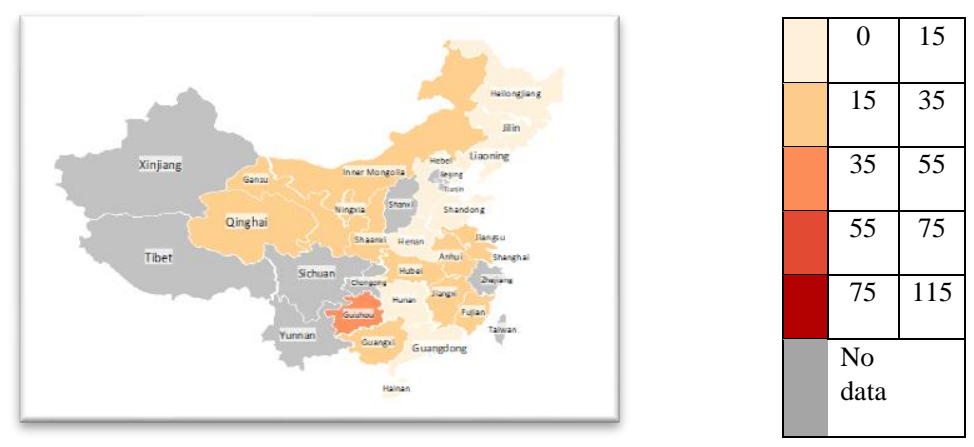


Graph 2. Number of beds in health institutions (per ten thousand persons) (1949-85)

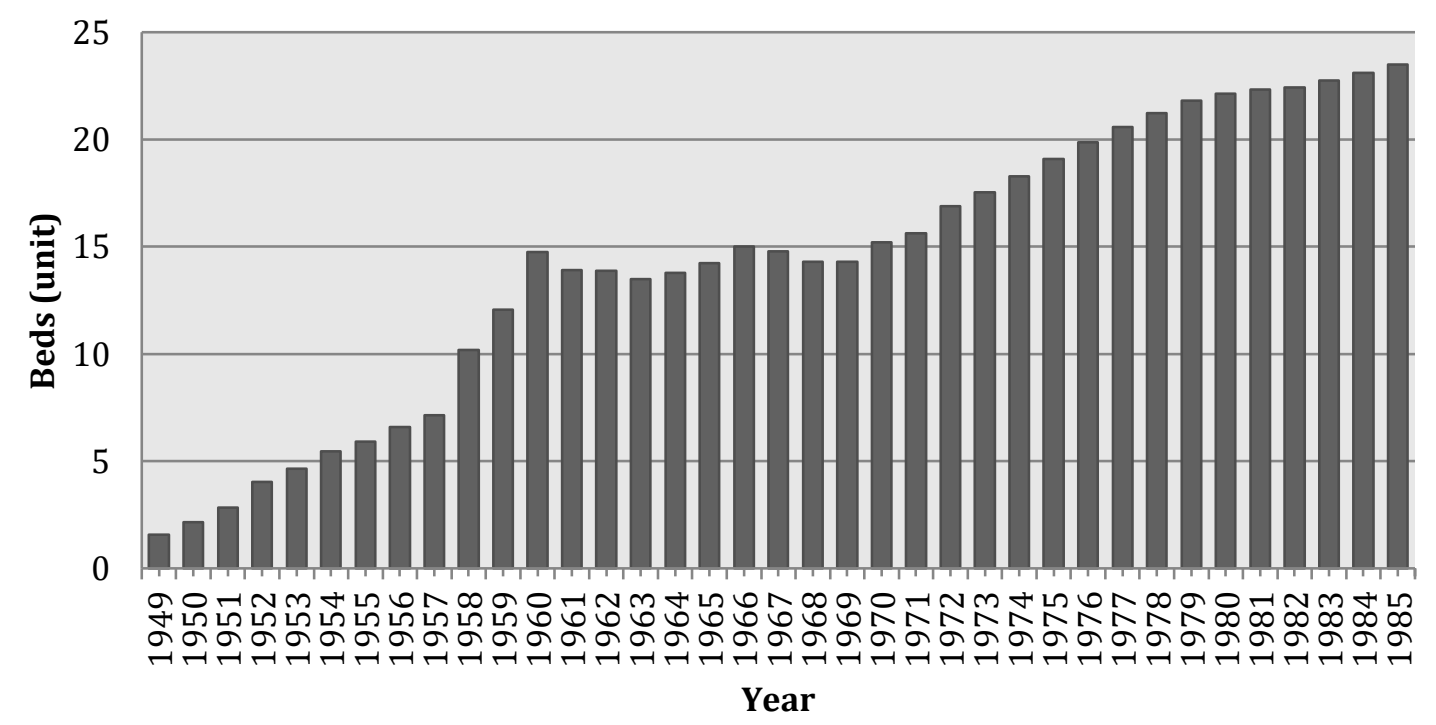

Source: Author's elaboration from the Comprehensive statistical data and materials on 50 years of new China (1950-1998) 
Table 1. Percentage of hospitals per province during the Maoist period (1949-76)

\begin{tabular}{|c|c|c|c|c|c|}
\hline Provinces & $\begin{array}{c}\begin{array}{c}\text { Initial } \\
\text { stage }\end{array} \\
1949-57\end{array}$ & $\begin{array}{c}\text { Great Leap } \\
\text { Forward } \\
\text { 1958-61 }\end{array}$ & $\begin{array}{c}\text { Adjustment } \\
\text { stage } \\
1962-65\end{array}$ & $\begin{array}{c}\begin{array}{c}\text { Cultural } \\
\text { Revolution }\end{array} \\
1966-76\end{array}$ & 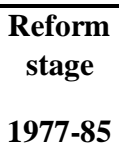 \\
\hline Beijing & 1,6 & 0,3 & 0,3 & 0,6 & 0,6 \\
\hline Henan & 4,5 & $42,(b)$ & 3,0 & 3,3 & 3,9 \\
\hline Tianjin & 1,1 & 0,1 & 0,1 & 0,1 & 0,5 \\
\hline Hebei & 5,9 & 3,5 & 4,6 & 6,8 & 6,6 \\
\hline Shanxi & 3,6 & & 1,0 & 3,6 & 3,6 \\
\hline Jilin & 2,4 & 1,9 & 0,8 & 1,9 & 1,9 \\
\hline Heilongjiang & 3,5 & 2,0 & 2,7 & 2,5 & 2,7 \\
\hline Shanghai & 5,9 & 1,1 & 1,2 & 0,7 & 0,7 \\
\hline Jiangsu & 3,3 & 5,1 & 1,3 & 3,7 & 3,8 \\
\hline Zhejiang & 3,6 & 8,7 & 0,8 & 5,5 & 5,4 \\
\hline Anhui & 2,8 & $24,8^{(\mathrm{b})}$ & 1,0 & 3,4 & 4,8 \\
\hline Fujian & 3,2 & 3,9 & 1,0 & 1,6 & 1,7 \\
\hline Jiangxi & 3,2 & 20,9 & 0,8 & 2,8 & 3,3 \\
\hline Shandong & 5,9 & 19,2 & 1,2 & 3,6 & 3,9 \\
\hline \multicolumn{6}{|l|}{ Hubei } \\
\hline Hunan & 4,3 & 12,1 & 1,2 & 6,8 & 6,7 \\
\hline Guangdong & 5,2 & & 3,5 & 2,9 & 3,0 \\
\hline Guangxi & 3,3 & 0,5 & 0,7 & 1,9 & 1,9 \\
\hline Yunnan & 4,0 & 3,5 & 0,6 & 2,7 & 2,8 \\
\hline Shaanxi & 3,8 & $20,1^{(b)}$ & 0,7 & 4,2 & 4,7 \\
\hline Gansu & 2,5 & 3,1 & 1,9 & 2,5 & 2,5 \\
\hline Qinghai & 0,7 & 0,2 & 0,1 & 0,2 & 0,8 \\
\hline Ningxia & 0,5 & 0,1 & 0,1 & 0,5 & 0,5 \\
\hline Xinjiang & 2,5 & 1,4 & 1,9 & 1,2 & 1,4 \\
\hline Hainan & 0,7 & 0,9 & 0,5 & 0,7 & 0,7 \\
\hline Inner Mongolia & 2,1 & & 1,0 & 2,5 & 2,7 \\
\hline $\begin{array}{l}\text { Remaining } \\
\text { provinces }^{\text {(a) }}\end{array}$ & 27,3 & $-88,7^{(\mathrm{c})}$ & 69,4 & 41,3 & 25,9 \\
\hline $\begin{array}{l}\text { Total hospitals in } \\
\text { China }\end{array}$ & 3.580 & 37.073 & 35.562 & 62.766 & 65.450 \\
\hline
\end{tabular}

Source: Author's calculation based on the Comprehensive Statistical Data and Materials on 50 Years of New China. Notes: (a) This group includes 9 additional provinces, where not data is available. We have estimated the percentage share of this group from the figures of the other 
provinces. (b) and (c) Our estimations give evidence that some figures were exaggerated during the GLF.

Table 2. Percentage of health institutions per province during the Maoist period (194976)

\begin{tabular}{|c|c|c|c|c|c|}
\hline Provinces & $\begin{array}{c}\begin{array}{c}\text { Initial } \\
\text { stage }\end{array} \\
1949-57\end{array}$ & $\begin{array}{c}\text { Great Leap } \\
\text { Forward } \\
\text { 1958-61 }\end{array}$ & $\begin{array}{c}\text { Adjustment } \\
\text { stage } \\
\text { 1962-65 }\end{array}$ & $\begin{array}{c}\begin{array}{c}\text { Cultural } \\
\text { Revolution }\end{array} \\
1966-76\end{array}$ & $\begin{array}{c}\begin{array}{c}\text { Reform } \\
\text { stage }\end{array} \\
\text { 1977-85 }\end{array}$ \\
\hline Beijing & 1,0 & 0,8 & 1,2 & 1,5 & 2,1 \\
\hline Henan & 5,4 & 11,6 & 7,9 & 4,3 & 4,4 \\
\hline Tianjin & 1,0 & 0,6 & 1,0 & 1,7 & 1,8 \\
\hline Hebei & 4,5 & 2,6 & 3,5 & 5,1 & 5,3 \\
\hline Shanxi & 7,2 & & 1,6 & 3,0 & 2,9 \\
\hline Jilin & 3,2 & 4,5 & 2,9 & 2,3 & 2,3 \\
\hline Heilongjiang & 3,7 & 2,0 & 2,6 & 3,8 & 4,7 \\
\hline Shanghai & 2,3 & 1,3 & 1,3 & 1,4 & 3,3 \\
\hline Jiangsu & 6,1 & 6,6 & 5,4 & 4,9 & 5,5 \\
\hline Zhejiang & 3,6 & 3,7 & 2,8 & 4,1 & 4,1 \\
\hline Anhui & 4,8 & 9,3 & 3,9 & 4,0 & 3,7 \\
\hline Fujian & 1,6 & 3,2 & 3,2 & 2,8 & 2,3 \\
\hline Jiangxi & 3,8 & 5,5 & 2,7 & 3,1 & 2,9 \\
\hline Shandong & 7,0 & 8,9 & 8,0 & 4,7 & 5,0 \\
\hline Hubei & 6,0 & 4,9 & 4,9 & 5,3 & 3,5 \\
\hline Hunan & 6,5 & 7,6 & 5,3 & 5,4 & 5,4 \\
\hline Guangdong & 3,9 & & 6,0 & 3,9 & 4,2 \\
\hline Guangxi & 5,4 & 5,7 & 2,7 & 2,7 & 3,0 \\
\hline Yunnan & 1,2 & 4,0 & 2,7 & 3,1 & 3,2 \\
\hline Shaanxi & 2,0 & 5,0 & 2,3 & 3,3 & 3,2 \\
\hline Gansu & 1,0 & 5,5 & 2,0 & 1,9 & 2,0 \\
\hline Qinghai & 0,2 & 0,9 & 0,4 & 0,6 & 0,6 \\
\hline Ningxia & 0,4 & 0,2 & 0,2 & 0,4 & 0,5 \\
\hline Xinjiang & 0,6 & 1,0 & 0,9 & 1,4 & 1,6 \\
\hline Hainan & 0,4 & 0,9 & 1,0 & 2,1 & 1,9 \\
\hline Inner Mongolia & 2,7 & & 1,7 & 2,8 & 2,4 \\
\hline Remaining provinces ${ }^{\text {(a) }}$ & 19,3 & $-0,6^{(\mathrm{b})}$ & 28,0 & 28,5 & 17,6 \\
\hline $\begin{array}{l}\text { Total health institutions in } \\
\text { China }\end{array}$ & 52.038 & 246.577 & 216.738 & 151.733 & 190.126 \\
\hline
\end{tabular}


Source: Author's calculation based on the Comprehensive Statistical Data and Materials on 50 Years of New China. Notes: (a) This group includes 9 additional provinces, where not data is available. We have estimated the percentage share of this group from the figures of the other provinces. (b) Our estimations give evidence that some figures were exaggerated during the GLF. 
Map 3. Allocation of doctors (per 10,000 inhabitants) in China (1949-85)

(a) Initial Satge (1950-57)

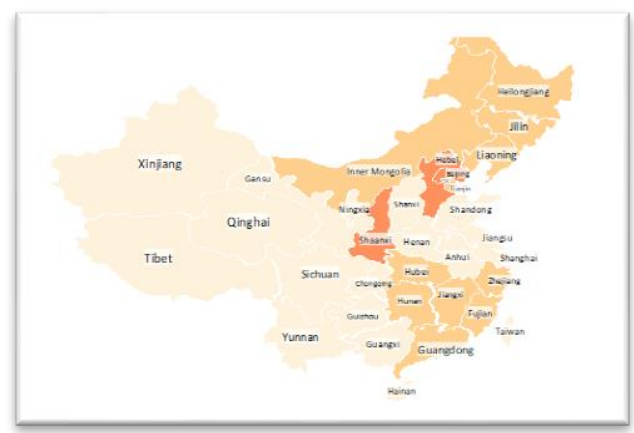

(d) Cultural Revolution (1966-76)

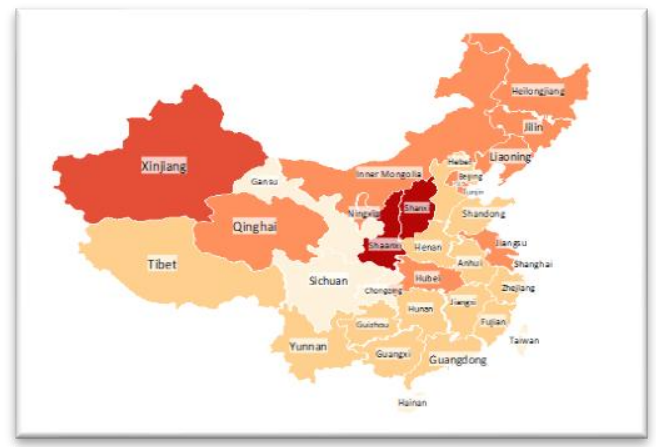

(b) GLF (1958-61)

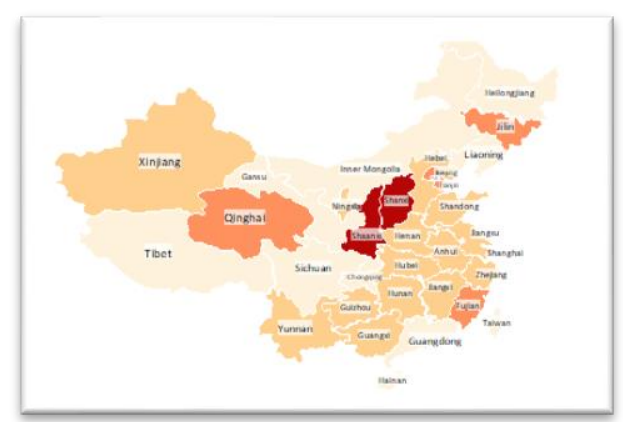

(e) First Economic Reforms (1977-85)

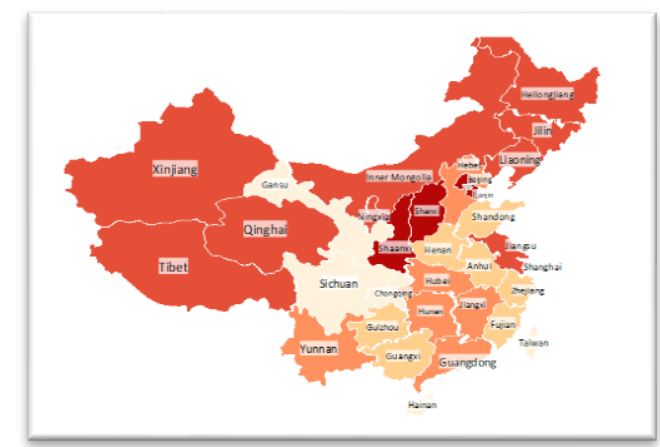

(c) Adjustment Stage (1962-665)

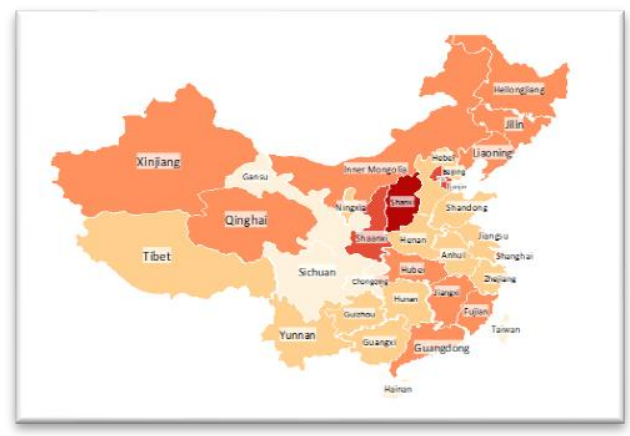

\begin{tabular}{|c|c|c|}
\hline & 0 & 5 \\
\hline 5 & 10 \\
\hline 10 & 15 \\
\hline 15 & 20 \\
\hline 20 & 40 \\
\hline
\end{tabular}

Source: Author's elaboration from the Comprehensive statistical data and materials on 50 years of new China (1950-1998) 
Graph 3. Number of medical technical personnel and doctors per ten thousand persons (1949-76)

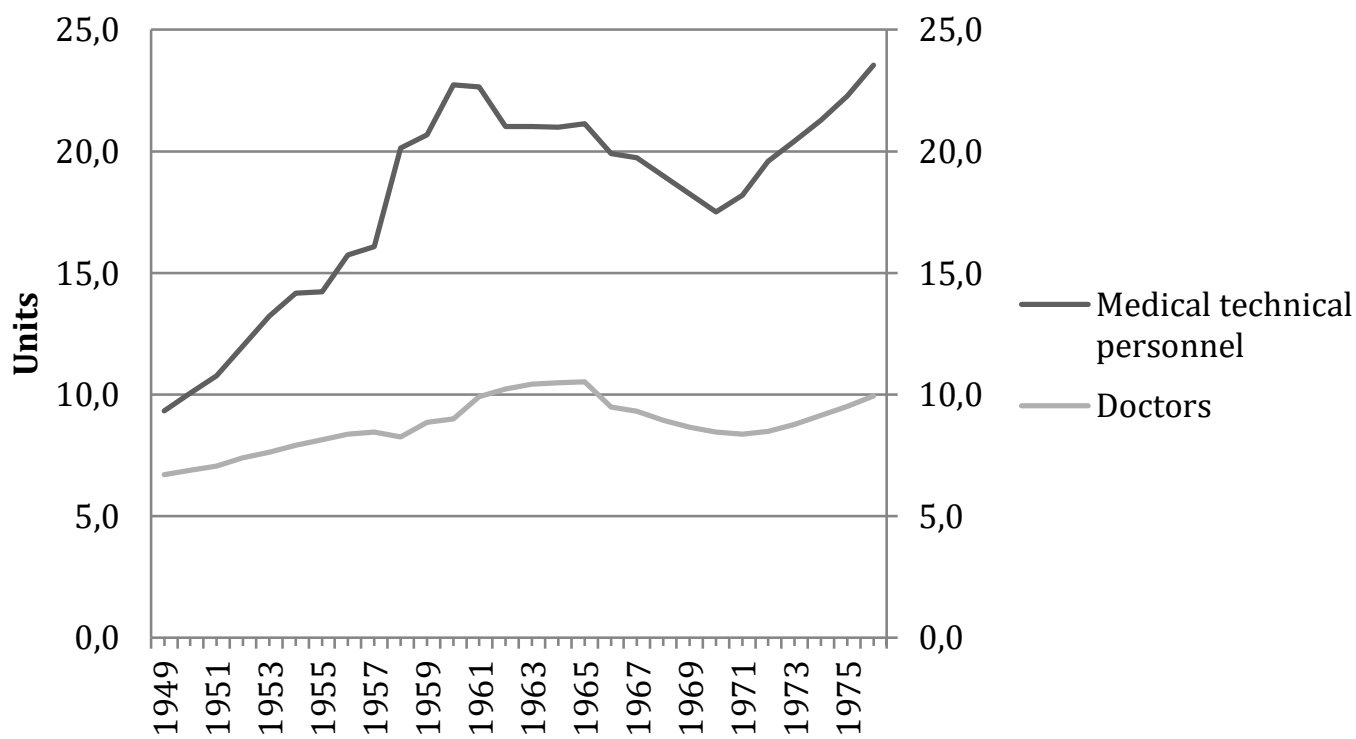

Source: Author's calculation based on the Comprehensive Statistical Data and Materials on 50 Years of New China

Graph 4. Number of doctors per ten thousand inhabitants in Henan province (1949-85)

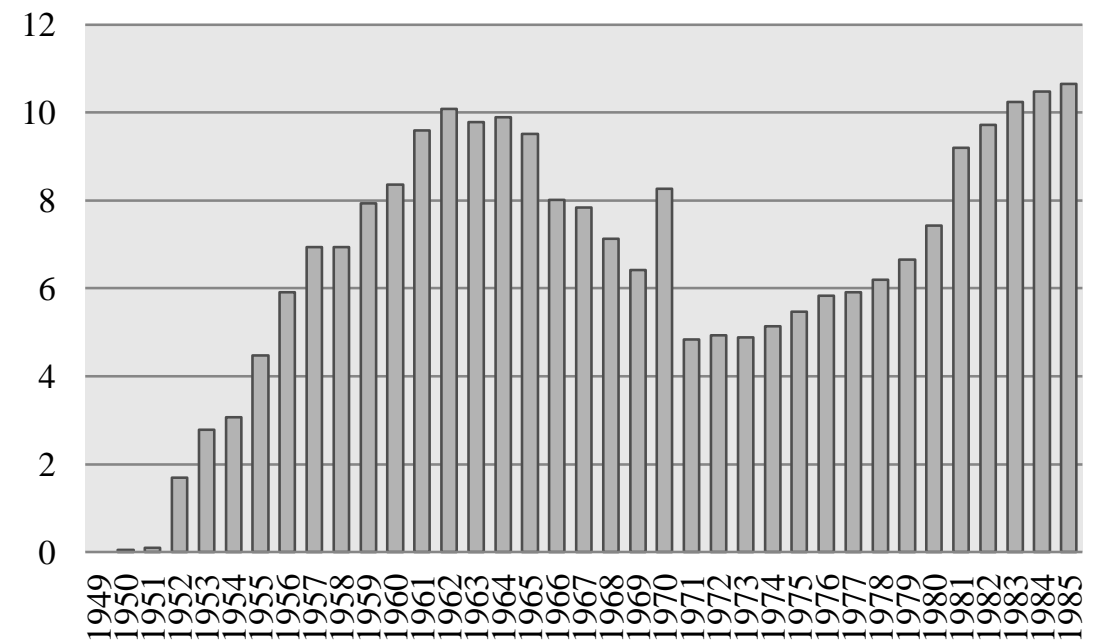

$\square$ Number of doctors (per 10000 persons)

Source: Comprehensive Statistical Data and Materials on 50 years of New China 
${ }^{1}$ Deaton, El Gran Escape. Salud; Li et al. "Exposure to the Chinese"; FAO, Nutrition and Consumer Protection; Popkin, "The nutrition transition" and "Will China's nutrition transition"; Popkin and Du, "Dynamics of the nutrition transition". Some of these studies are based on health surveys conducted in China in recent decades such as the China Health and Nutrition Survey (CHNS), which has rich information about individual and household health since the late 1980 s

${ }^{2}$ Whyte and Sun, "The impact of China's market"; Kwon and Schafer, "Improving but unequal"; Li and Wei, "Multidimesional inequality in health"

3 Zhu, "Current approaches to social"; Keidel, "Chinese regional inequalities"

${ }^{4}$ Evadrou et al. "Individual and province inequalities"; Biao, "How far are the left-

behind"; Feng et al. "An exploratory multilevel analysis"; Yin and Lu, "Individual and community factors"; Zhao, "Income inequality, unequal health"; Chou and Wang, "Regional Inequality in China's Health"

${ }^{5} \mathrm{Li}$ and Wei, "Multidimensional inequality in health"; Pan and Shallcross, "Geographic distribution of hospital beds"; Zhang, et al. "Study on equity and efficiency"; Qin and Hsien, "Economic growth and the geographic maldistribution"

${ }^{6} \mathrm{Zhu}$, "Current approaches to social protection"

${ }^{7}$ White, "From "Barefoot Doctor" to"; Brown et al. "Reforming Health Care in China"

${ }^{8}$ White, "From "Barefoot Doctor" to"; Hipgrave, "Commutable disease control in China"

${ }^{9}$ Huang, Governing Health in Contemporary China

${ }^{10}$ Ibid.

${ }^{11}$ Slaff, "Mortality decline in People's Republic"; Mason et al. "The decline of infant mortality"; Campbell, "Mortality Change and the Epidemological"; Banister and Zhang, "China, Economic Development and Mortality"; Chen and Zhou, "The long-term health and economic"; Hipgrave, "Commutable disease control in China"; Song and Burgard, "Dynamics of inequality"

${ }^{12}$ Jamison et al., China: the health sector; Babiarz et al. "An exploration of China's mortality"

${ }^{13}$ Andersen et al. Changing the US health care system; Horev et al. "Trends in geographic disparities"; World Health Organization, World health report

${ }^{14}$ Pan and Shallcross, "Geographic distribution of hospital"

${ }^{15}$ Yip, "Disparities in health care"

${ }^{16}$ Notice that even though the health resources have increased since the economic reforms, the privatization of the health system has led to unequal access of these resources (Hu et al. "Reform of how healthcare is paid"; Wagstaff and Lindelow, "Health Reform in Rural China"; Yip and Hsiao, "China's Health Care Reform:"; Li and Wei, "Multidimensional inequality in health"). On the other hand, for most of the Maoist period, the health system was state-owned, and therefore, the allocation of the health inputs had greater relevance to understand health output and inequality, than the income of households.

${ }^{17}$ This new dataset developed by the Stanford University and Central University of Finance and Economics has recently been available to the public. The dataset includes health records at a provincial level from 1950 to 1988. Find additional information at (Babiarz et al. "An exploration of China's mortality")

${ }_{18}$ Alvarez-Klee "The Biological Standards of living"

${ }^{19}$ Seventy-five per cent of hospital beds and 62 per cent of the senior Western-style physicians were located in urban areas (Huang, 2013: pp. 41). Notice that at this point in history over 90 per cent of the population was located in the rural areas.

${ }^{20}$ Perkins and Yusuf, 1984, pp.135

${ }^{21}$ Huang, Governing Health in Contemporary China, 44

${ }^{22}$ Hipgrave, "Commutable disease control in China "225

${ }^{23} \mathrm{Xu}$, "Control of communicable diseases" 
${ }^{24}$ Huang, Governing Health in Contemporary China, 45; Li Rui, Li Rui “zuo” wenxuan, 276; Perkins and Yusuf, Rural Development in China, 137).

${ }^{25} \mathrm{Xu}$ Yunbei, Kaizhan weida de renmin weisheng gongzuo, 10).

${ }^{26}$ Huang, Governing Health in Contemporary China , 48).

${ }^{27}$ Ibid. 50

${ }^{28}$ Other reasons attributed to the famine are natural disasters and the elimination of all sparrows in rural areas, which contributed to locust pest. However, main reasons are contributed to political and institutional setbacks in the GLF.

${ }^{29}$ Huang, Governing Health in Contemporary China , 54; Hipgrave, "Commutable disease control in China, 226

${ }^{30}$ Ministry of Health, Research of National Health Services

${ }^{31}$ MacFarquhar and Schoenhais, Mao's Last Revolution, 26).

${ }^{32}$ Miao Yu, 1976, pp.7; Li Zhisui, 1994, p.419-20).

33 (Dobson, 1981, pp.43; Huang, 2013, pp.57)

34 (Hu The-wei, 1976)

35 (Wu Chieh-ping, 1975, pp.10; Hipgrave, 2011, pp.227)

36 (Lee, 1974)

37 (Cook, 2004; Huang, 2013)

38 (Banister, 1987; Bien, 2008; Hipgrave, 2011)

${ }^{39}$ (Song and Burgard, 2011; Wang and Yang, 1996, pp. 303; Babiarz, 2015; pp. 5)

${ }^{40}$ (Comprehensive Statistical Data and Material on 50 years of New China, 1950-98)

${ }^{41}$ (Huang, 2013)

${ }^{42}$ (Henan Sheng Zhi, 1949-85)

${ }^{43}$ (Pan and Shallcross, 2016)

\section{References}

Alvarez-Klee (submission date Summer 2018) "Nutritional Status in China during the Maoist period (1949-76)". Barcelona: University of Barcelona

Andersen R., Rice T., Kominski, G. (2011) Changing the US health care system: Key issues in health services policy and management. San Francisco: Wiley

Babiarz, K., Eggleston, K., Miller, G., and Zhang, Q. (2014) “An exploration of China's mortality decline under Mao: A provincial analysis, 1950-80)", Population Studies: A Journal of Demography, (p. 1-18)

Banister, J. (1987) China's Changing Population. Stanford, CA: Stanford University 
Press

Banister, J. and Zhang, X. (2005) "China, Economic Development and Mortality Decline" World Development, Vol. 33, Issue 1 (p.21-41)

Biao, X. (2006) "How far are the left-behind left behind? A preliminary study in rural China” Pop. Sp. Place, Vol. 13, 179-191

Bien, CH. (2008) “The Barefoot Doctors: China's rural health care revolution, 1968-1991 [Honors Thesis]. Middle-town, CT: Wesleyan University

Brown R., Garcia D., Liu Y., and Moore J. (2012) "Reforming Health Care in China. Historical, Economic and Comparative Perspectives" Pubpol 716

Campbell C. (2001) "Mortality Change and the Epidemological Transition in Beijing, 1644-1990”. In: Liu Ts'ui-jung, et al., editors. Asian Population History. Oxford University Press; Oxford (p. 221-247)

Chen Y. and Zhou L., "The long-term health and economic consequences of the 1959-61 famine in China" Journal of Health Economics, Vol. 26 (p. 659-681)

Chou, W.L. and Wang, Z.J. (2009) "Regional Inequality in China's Health Care Expenditures" Health Economics, Vol. 18 (p.S137-S146)

Cook, D. (2004) "Changing Health in China: re-evaluating the epidemiological transition model”, Health Policy Vol. 67, p. 329-343

Deaton, A. (2015) El Gran Escape. Salud, riqueza y los orígenes de la desigualdad. Madrid: Fondo de Cultura de España

Department of Comprehensive Statistics of National Bureau of Statistics (1999) 
Comprehensive Statistical Data and Materials on 50 Years of New China [Xin Zhongguo

Wushi Nian Tongji Ziliao Xupian]. Beijing: China Statistics Press

Devereux, S. (2000) "Famine in the twentieth century" IDS Working Paper 105, Brighton: IDS

Dobson, A. (1981) "Health care in China after Mao", Health Care Financing Review, (p. 41-53)

Evandrou, M., Falkingham, J., Feng, Z., Vlachantoni, A. (2014) "Individual and province inequalities in health among older people in China: Evidence and policy implications", Health and Place, Vol. 30 (p.134-144)

FAO (2010) Nutrition and Consumer Protection. China Summary. http://www.fao.org/ag/agn/nutrition/chn_en.stm, accessed 03 November, 2012.

Feng, Z., Wang, W., Jones, K., and Li, Y. (2012) “An exploratory multilevel analysis of income, income inequality and self-rated health of the elderly in China" Social Science and Medicine, Vol. 75, Issue 12, (p.2481-2492)

Horev T., and Pesis_Katz I. (2004) "Trends in geographic disparities in allocation of health care resources in the U.S.” Health Policy, Vol. 68 (p.223-32)

Hipgrave, D. (2011) “Commutable disease control in China: From Mao to now”, Journal of Global Health, Vol. 1, No. 2 (p. 224-238)

Hu The-wei (1976) "The financing and the economic efficiency of rural health services in the People's Republic of China", International Journal of Health Services, Vol.6, No. 2 (p. 239-49)

Hu, SL., Tang YL., Liu YX, Zhao, Escobar ML., and Farranti, DD. (2008) "Reform of 
how healthcare is paid for in China: Challenges and opportunities" Lancet 372 (p. 18461853)

Huang, Y. (2013) Governing Health in Contemporary China. New York: Routledge

Jamison D., Evans J., King T., Porter I., Prescott N. Prost A (1984) China: the health sector. Washington, D.C.: World Bank

Keidel, A. (2009) "Chinese regional inequalities in income and well-being”. Review of Income and Wealth, Series 55, Special Issue 1

Kwon, S. and Schafer, M. (2016) "Improving but unequal: Temporal trends in Chinese self-rated health, 1990-2012. Population Health, Vol. 2, p. 77-83

Lee, PR. (1974) "Medicine and Public Health in the People's Republic of China", The West Journal of Medicine, 120 (p. 430-37)

Li, Y., Jaddoe, V., Qi, L., Wang, D., Lai, J., Zhang, J., Fu, P., Yang, X., Hu, F. (2011). "Exposure to the Chinese famine in early life and the risk of metabolic syndrome in adulthood”. Diabetes Care, 34(4), 1014-1018.

Li Rui (1995) Li Rui “zuo” wenxuan [Selected Anti-leftist Works of Li Rui]. Beijing: Zhongyang bianyi chubanshe

Li, Y. and Wei, D. (2014) "Multidimensional inequality in health care distribution in provincial China: A case study of Henan Province" Royal Dutch Geographical Society, Vol. 105, No. 1 (p. 91-106)

Li, Y. and Wei, D. (2010) “A Spatial-Temporal Analysis of Health Care and Mortality Inequalities in China" Eurasian Geography and Economics, Vol. 51, Issue 6 (p. 767-787) 
Li Zhisui (1994) The private life of Chairman Mao. New York: Random House

MacFarquhar, R. and Schoenhals, M. (2006) Mao's Last Revolution. Cambridge and London: Harvard University Press

Mason W., Lavely W., Ono H., Chan A. (1996) “The decline of infant mortality in China:

Sichian, 1949-1988”. In: Baron JN, et al., editors. Social Differencentiiation and Social Inequality: Essays in Honor of John Pock. Westview Press; Boulder, Colorado (p.153207)

Ministry of Health (1999) Research of National Health Services [Guojia weisheng fuwu yanjiu]. Beijing: $\mathrm{MOH}$

Pan, J. and Shallcross, D. (2016) "Geographic distribution of hospital beds throughout China: a county-level econometric analysis" Int J Equity Health, Vol. 15 (p.179)

Perkins, D. and Yusuf, S. (1984) Rural Development in China. Baltimore, MD: Johns Hopkins University Press

Popkin, B. (1997). The nutrition transition and its health implications in lower income countries. Public Health Nutrition, 1(1), (p. 5-21).

(2008). Will China's nutrition transition overwhelm its health care system and slow economic growth? Health Affairs, 27(4).

Popkin, B., Du, S. (2003) "Dynamics of the nutrition transition toward the animal food sector in China and its implications: a worried perspective" The Journal of Nutrition, 133 (11). 
Qin, X. and Hsien, C.R. (2014) "Economic growth and the geographic maldistribution of health care resources: evidence from China, 1949-2010" China Economic Review, Vol. 31 (p. 228-46)

Salaff J (1976) "Mortality decline in People's Republic of China and the United States" Population Studies, Vol. 27 (p. 551-576)

Song, S. and Burgard, S. (2011) "Dynamics of inequality: mother's education and infant mortality in China 1970-2001, Journal of Health and Social Behaviour, Vol. 53, No. 3 (p. 349-364)

$\mathrm{Xu}, \mathrm{X}$. (1994) "Control of communicable diseases in the People's Republic of China" Asian Pacific Journal Public Health, (p. 123-131)

Xu Yunbei (1960) Kaizhan weida de renmin weisheng gongzuo [Launch a movement for great people's health work], Hongqi [Red Flag], (6)

Wagstaff, A. and Lindelow, M. (2008) "Health Reform in Rural China: Challenges and Options". In: Lou, J. and Wang, S. eds. Public Finance in China: Reform and Growth for a Harmonious Society (p. 265-286). Washington D.C.: World Bank

Wang (2011) "The future of a demographic overachiever: Long-term implications of the demographic transition in China", Population and Development Review, Vol. 37 (pp. 173-190)

Wang, F. and Yang, Q. (1996) "Age at marriage and the first birth interval: the emerging change in sexual behavior among young couples in China", Population and Development Review, Vol. 22, No. 2 (p. 299-320) 
Whyte, M.K. and Sun, Z. (2010) “The impact of China's market reforms on the health of Chinese citizens: examining two puzzles" China an International Journal, Vol. 8 (p.132)

White, S. (1998) "From “Barefoot Doctor" to "Village Doctor” in Tiger Springs Village: A case study of Rural Health Care Transformations in Social China", Human Organization, Vol. 57, No. 4 (p. 480-490)

World Health Organization (WHO) (2000) World health report. Geneva: World Health Organization.

Wu Chieh-ping (1975) "For workers, peasants, and soldiers", Peking Review, Vol. 8 (February)

Yin, D., and Lu, J. (2007) "Individual and community factors associated with activities of daily living among the oldest-old, an application of the HLM method" Popul. Res. Policy Rev. (p.60-70)

Yip, W. (2009) "Disparities in health care and health status: the rural-urban gap and beyond". In: Whyte M., editor. One country, two societies: rural-urban inequality in contemporary China. Cambridge MA: Harvard University Press

Yip, W. and Hsiao, W. (2009) “China's Health Care Reform: A Tentative Assessment”, China Economic Review 20 (p.613-619) 
Yu Miao (1976) Counterattack the right-est rehabilitation wind in the health sector [Fanji weisheng zhanxian de youqing fanan feng], Red Flag [Hongqi] (4)

Zhang, X., Zhao, L., Cui, Z., Wang Y., (2015) "Study on equity and efficiency of health resources and services based on Key indicators in China" PLoS One, Vol.12

Zhao, Z. (2006) "Income inequality, unequal health care access, and mortality in China" Population and Development Review, Vol. 32 (p.461-483)

Zhu, Y. (2013) “Current approaches to social protection in China”... In: Midgley, J. Piachuad, D. (eds.), Social Protection, Economic Growth and Social Change, Goals, Issues and Trajectories in China, India, Brazil, and South Africa. Cheltenham: Edward Elgar

\section{Archives}

\section{Websites}

